\title{
Una Contrata Inédita, Dos Programas y Noticias Referentes al Teatro en Bogotá entre 1838 y $1840^{1}$
}

I A contrata aquí considerada se encuentra inédita en el Archivo Histórico Nacional de Bogotá y a mi parecer merece ser publicada, por la luz que derrama sobre las condiciones e individuos que daban representaciones teatrales en la capital de Colombia en 1838, año que cae hacia el fin del período de regeneración, o más bien de creación, del teatro bogotano. ${ }^{2}$ En la primera parte del documento, firmada el 29 del mes de noviembre, se estipulan los derechos y obligaciones del director y de los actores individuales. Se comprometen todos no sólo a actuar, sino también a escribir, preparar copias de música y de drama, coser los vestuarios para comparsas y ayudar por turno con el aparato de escena. Para atender los intereses del grupo, se propone nombrar una junta que revise las cuentas, considere los contratos de cómicos que en el futuro se unan a la compañía y autorice con su consentimiento el pedir préstamos para viajes, etc. Nadie tendrá derecho a dejar la compañía sin el permiso de la junta y del director. Se repartirán los papeles para la mejor ejecución de la representación, es decir, conforme a la capacidad de los individuos.

E1 director estará encargado de las cuentas de la compañia, de entregar las boletas y de hacer los preparativos necesarios para la función. El y la junta tendrán la responsabilidad de mantener el buen orden en el vestuario. No entrarán sin pagar más que los criados que trabajan con los actores. Visto que la compañía es responsable en el caso de deudas contraídas con su consentimiento, no serán 
pagaderas sin presentarse los recibos de los artesanos que hayan cobrado por sus servicios. Al socio sólo podrán eximirle del trabajo a causa de enfermedad comprobada. Se pagarán los gastos de viaje de los fondos de la compañía, pero si no bastan, el director, con el previo consentimiento de la junta, tomará los fondos necesarios a crédito; los gastos para cabalgaduras se determinarán según el sueldo del individuo. Se propone reunir tan pronto como sea posible un fondo común, que procederá del producto de una función mensual extraordinaria. Si un socio perjudica a la sociedad por su mala conducta, estarán autorizados la junta y el director a reprenderle tres veces y al fin a excluirle de la compañía, cuando tal paso parezca preciso. Será obligatoria la asistencia a los ensayos, salvo causa justificada. La junta determinará el tanto de sueldo que toque a los individuos, no miembros de la compañía, por su trabajo. El señor Agustín Ramos, además de dirigir la orquesta y tocar el primer violín, tendrá a su cargo todo lo referente a la música.

Se indican los sueldos por partido ${ }^{3}$ que se pagarán a cada uno de los socios, suministrando así alguna idea de la proporción de la recompensa recibida por servicios de teatro y descubriendo el personal de la compañía. Ninguno que se agregue a la compañía podrá recibir sueldo mayor que el del primer galán o del director. Entre los nombres de actores que aparecen, encontramos individuos que contribuyeron bastante al desarrollo del teatro en Bogotá en el siglo xIx. Francisco Martínez, gracioso, apellidado popularmente "El Curro", y la segunda dama cantatriz, Juliana Flécher - "una alcachofa marchita" - según Pepe Escallón, habían venido al país a principios de 1833 con Francisco Villalba, director de la primera. verdadera compañía dramática que dió representaciones en Bogotá. ${ }^{4}$ En el año de 1836 los dos, todavía miembros de la entonces muy acrecentada compañía de Villalba, volvieron de Chile y del Perú. Agustín Ramos tocaba el violín en la orquesta de dicha compañía. Francisco Gallardo, su esposa Marieta Abadía y Victoriano Rendón descollaron también entre los principales socios de la compañía que iba siendo organizada. E1 joven Rendón, galán y gracioso inimitable, aunque no poeta, solía recitar poesías ante el público fingiendo improvisarlas. Marieta era excelente cantatriz, mientras Gallardo se captaba los aplausos de todos en el papel de primer galán. Éste hizo imprimir en Cartagena un tomo de sus versos y en Maracaibo se dió su tragedia titulada Henrique $I I I .^{5}$ 
Además estipula la contrata que cada uno debe tener disponible para la corporación, sin pago alguno, su surtido de piezas de drama o de música y hasta el vestuario; naturalmente, el último caso se limita con ciertas restricciones. Se especifica que los beneficios particulares, práctica muy arraigada en el teatro español y traída al Nuevo Mundo, se verifiquen mensualmente, dejando la elección de la obra al individuo o individuos en cuyo honor se dé el festival. El primero de los artículos adicionales manifiesta que la compañía está compuesta de individuos que antes pertenecían a la compañía del señor Martínez y a la del señor Eduardo Torres, y que se propone dejar en el fondo la tercera parte del sueldo que corresponda a cada uno de éstos, para ir pagando los créditos pendientes. El segundo adicional encarga al señor Rendón, entendido en la escenografía, que dirija las pinturas. Once firmas ponen fin a esta parte del instrumento, que lleva la fecha del 29 de noviembre de 1838. El 6 del mes siguiente fueron elegidos miembros de la junta los señores Gallardo, Rendón y Flores. Francisco Martínez sirve de director.

El 20 de diciembre se reúnen los socios con el español Eduardo Torres, quien habla por sí y por stu familia, para firmar el documento que legaliza la formación de una sola compañía de los dos grupos. Se introducen en la contrata ciertas modificaciones en lo referente al señor Torres y su familia: poder separarse al marchar la compañía, recibir el tanto que le corresponda a él y a su familia por cada función, no prestar los vestidos, tener sus beneficios, etc. Piensan dar cuatro funciones supernumerarias, con la esperanza de pagar las deudas. Al dia siguiente, puesto que el señor Torres se opone a la permanencia de la junta, se vota disolverla y delegar todos sus derechos al director Francisco Martínez. La familia de Torres estaba compuesta de él mismo, su señora, sus hijas Enriqueta y Eloísa, y el señor Requejo (hermano de la señora de Torres). Enriqueta, joven de diecisiete años, se granjeaba el aplauso y adoración del público bailando la jota aragonesa, vestida de hombre con chaquetilla y calzón corto. ${ }^{6}$

Las noticias en el semanario bogotano El Argos, indican que la recién formada compañía, dirigida por los señores Martínez y Torres (éste había traído su familia de Cartagena), dió su primera función la noche del 16 de diciembre. ${ }^{7}$ Se estrenó la nueva compañía con el drama histórico titulado Torcuato Tasso, escrito en francés por A. Duval y traducido al español por Ventura de la Vega. ${ }^{8}$ La pren- 
sa no tuvo más que elogios para los méritos de los comediantes. El señor Gallardo hizo el papel del desgraciado poeta. ${ }^{9}$ El anuncio ${ }^{10}$ de la primera función, reproducido aquí en facsímile, muestra que durante el intermedio cantó la señora Marieta Abadía un aria de la ópera El barón de Felchen (letra de Romani y música de Pacini) ${ }^{11}$ y que el señor Rendón desempeñó los papeles de cinco personajes distintos en la pieza en un acto Las tramas de Garulla (también conocida con el título Las trazas de Garulla, por Zabala y Zamora, según Salvá), ${ }^{12}$ la que concluyó la función. Al final este documento lleva una tarifa de los precios. Por noche valía un palco del patio, 2 pesos; uno de en medio, 3 pesos; uno alto, 1 peso con 4 reales; la entrada general, 4 reales. La temporada iba a constar de doce funciones.

Entre el 23 de diciembre de 1838 y el 3 de marzo de 1840 representó la compañia las siguientes piezas dramáticas de su repertorio, todas, con dos excepciones, ya estrenadas en España: Un tercero en discordia, por Bretón de los Herreros; Un paseo a Bedlán o la reconciliación por la locura, escrita por Scribe y traducida por Bretón de los Herreros; Marcela, por Bretón de los Herreros; El rey valiente y justiciero, y rico hombre de Alcalá, adaptación por Dionisio Solís de El rico hombre de Alcalá, por Moreto; Polder o el verdugo de Amsterdam, por Juan Lombía, de Le gamin de Paris, de Bayard y Vanderburch; Marido joven y mujer vieja, acomodada al teatro español por D. R. de M.; No más mostrador, adaptación por Larra de Le portrait de Michel de Cervantes de Dieulafoy y de Les adieux au comptoir de Scribe; Quince años ha (o el campo y la corte), arreglada del drama francés por Víctor Ducange; La llave falsa (o los dos hijos), traducida por Bretón de los Herreros; Angelo, tirano de Padua, por Víctor Hugo, traducida al castellano por Sáenz (representada dos veces); Los dos maridos solteros, por Scribe; El dormido despierto, o aventuras del Califa de Bagdad, drama en cinco actos; El alcalde médico, entremés por Moraleja; La recompensa del arrepentimiento, por D. A. M. y E. (Marqués y Espejo, según Máiques, pág. 412) ; Los accidentes de una fiesta, o el jugador de manos, en tres actos, arreglada del francés, por Gabriel José García; El marido de seis mujeres, acaso sea La frontera de Saboya, o el marido de tres mujeres, escrita en francés por Scribe y traducida por Narciso de la Escosura, o El marido de dos mujeres, de una obra por Scribe y de Valentine, por Mélesville; Miguel y Cristina, escrita 


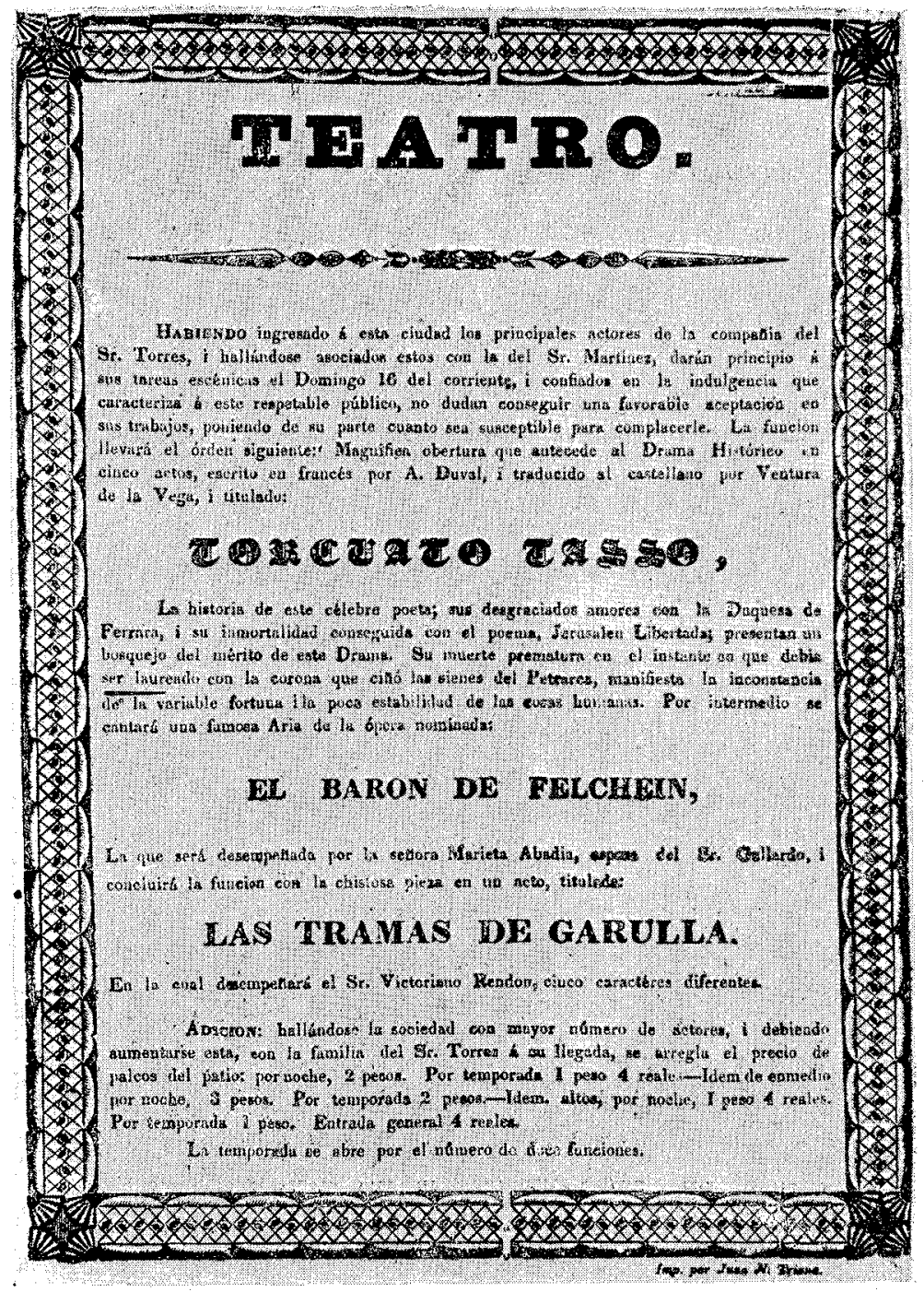




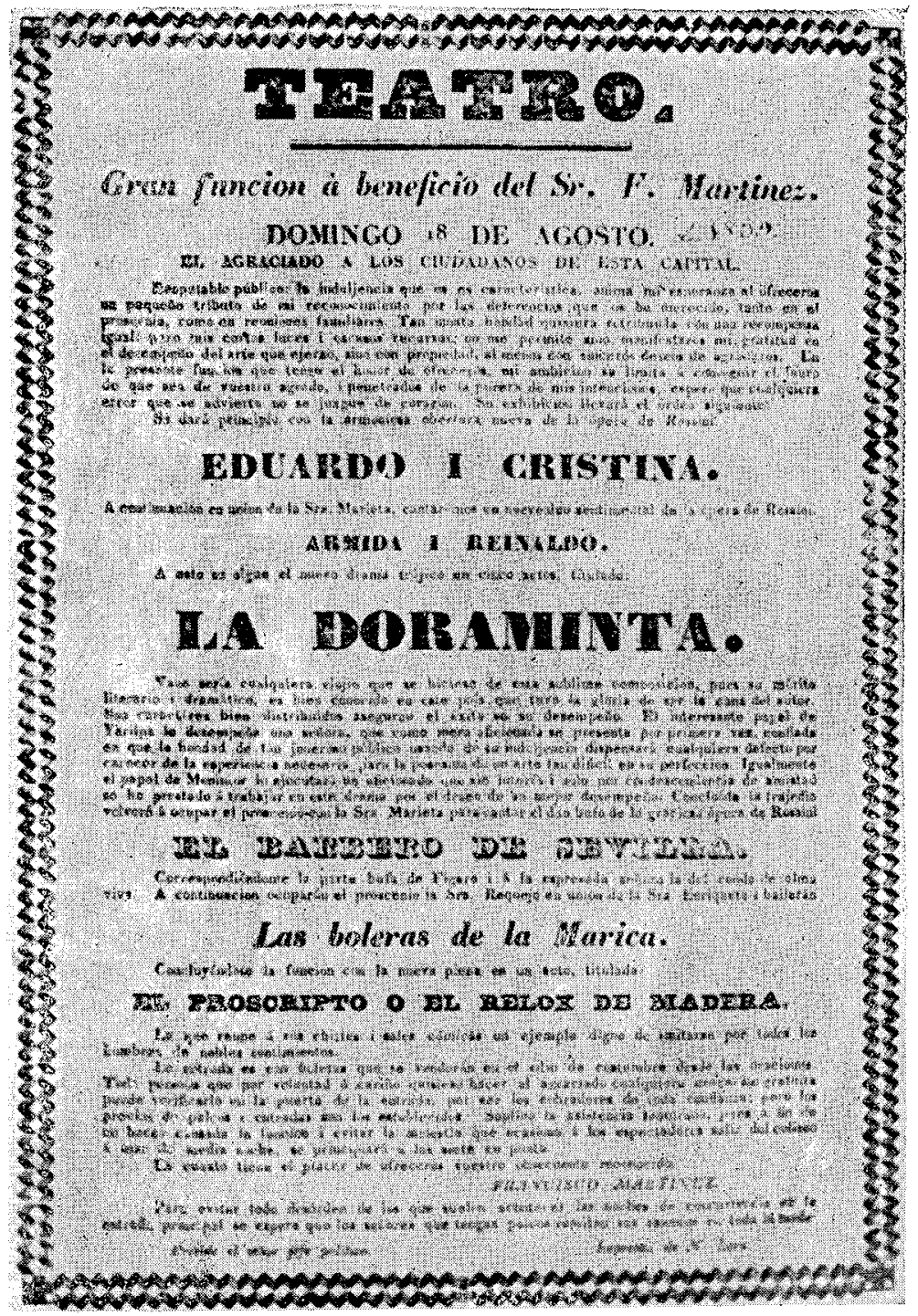


por Scribe y Dupin y traducida al castellano por Ventura de la Vega; La herencia y el parentesco o los hermanos a la prueba, traducción del drama francés Les frères à l'épreuve, de Pelletier-Volméranges (según Máiquez, pág. 331) ; La máquina maravillosa, petipieza (representada dos veces); Don Iuan de Austria, por Casimir Delavigne y arreglada al castellano por Larra; Un trío en Indias, por Scribe; El especiero, o el marido de tres mujeres, pieza en un acto, por Scribe, traducida por Escosura; (El hijo con dos padres) o la incertidumbre filial, drama en tres actos, del francés de Mr. de Mircourt (según Máiquez, pág. 413); La vuelta de Estanislao, por Scribe, traducida y arreglada por Ventura de la Vega, continuación de $M i$ guel y Cristina (representada dos veces); La intriga fraternal, drama en tres actos (representada tres veces); El abate de L'Epée, por Jean Nicolás Bouilly, traducida al castellano por Juan de Estrada; La vieja y los dos calaveras, pieza en un acto en prosa (según Máiquez, pág. 396), representada veintinueve veces en Madrid entre 1821 y 1833; La Doraminta, por Luis Vargas Tejada; La pirámide de Fabio, por José Manuel Royo; El preceptor de su hijo, en dos actos, conocida también con los títulos El ayo de su hijo y Los dos ayos, atribuída a Comella o quizás del francés de Fabre d'Eglantine (representada dos veces); Los caprichos de Catalina II, por Scribe (representada dos veces); Inocencia, robo e intriga, también intitulada La inocencia y la intriga o el robo y La inocencia y la intriga, los ladrones de Marsella, representada once veces en Madrid entre 1822 y 1831; El médico del difunto, traducida por Bretón de los Herreros (representada dos veces); Los treinta años, o la vida de un jugador, por Ducange y Dinaux (Dinaux es el seudónimo de Beudin y Goubeaux), traducida y arreglada al español por Magnolio Juárez, seudónimo de Salvador Suñer Farrés; El triunfo de la virtud y destrucción de la inquisición, por Eugenio de Ochoa. ${ }^{13}$

Analizando la lista de arriba se nota que sólo se pusieron en escena dos obras de dramaturgos colombianos: La Doraminta y La pirámide de Fabio, selecciones, según el crítico de El Censor, que manifestaron poco tino por parte del director. ${ }^{14}$ Está reproducido aquí en facsímile el programa ${ }^{15}$ que ofreció al público La Doraminta para el domingo 18 de agosto de 1839. La función, a beneficio del señor Francisco Martínez, ${ }^{16}$ comenzó a las siete con la obertura de Eduardo y Cristina, que fué seguida por un dúo de Armida y Reinaldo, ambas óperas de Rossini. Dos aficionados hicieron respecti- 
vamente los papeles de Yarilpa y Menintor en la tragedia de Vargas Tejada. Terminada ésta cantaron el beneficiado y la señora Marieta un dúo de El barbero de Sevilla. Después de bailadas las Boleras de la Marica fué concluída la función con la representación de El proscripto o el relox de madera, pieza en un acto.

También se deduce de la lista de piezas representadas que no dominaban exclusivamente ni el género clásico, ni el romántico, ni las comedias de costumbres, ni las de enredo. $\mathrm{Y}$ asimismo se infiere que las traducciones y adaptaciones del francés eran tan aplaudidas en Bogotá como en Madrid. ${ }^{17}$ En efecto, en este breve catálogo se ve en seguida que buena parte de las obras son traducciones. La gran proporción de piezas de Scribe nos recuerda el sarcasmo de Larra: "- ¿Qué se da en el teatro? dice uno-- Aquí: 1" sinfonía; $2^{\circ}$ pieza del célebre Scribe; $3^{\circ}$ sinfonía; $4^{\circ}$ pieza nueva del fecundo Scribe; $5^{\circ}$ sinfonía; $6^{\circ}$ baile nacional; $7^{\circ}$ la comedia nueva en dos actos, traducida támbién del ingenioso Scribe; $8^{\circ}$ sinfonía; $9^{\circ} \ldots$ -Basta, basta; ; santo Dios!" 18 Bretón de los Herreros ocupaba el segundo puesto desde el punto de vista del número de las comedias originales y traducciones representadas. Larra y Ventura de la Vega gozaban de cierta popularidad. Uno se maravilla de ver que a veces habían transcurrido no más que tres o cuatro años entre el estreno de París y el de Madrid y la representación en Bogotá: por ejemplo, Ángelo, estrenada en 1835 en París y representada cuatro meses después en Madrid; El pilluelo de París, estrenada en enero de 1836 en París y a fines del mismo año en Madrid, donde inmensas concurrencias la aplaudieron a rabiar. ${ }^{19} \mathrm{El}$ crítico literario de El Argos objetó en general a la representación de dramas del antiguo teatro español y en particular a la de El rey valiente y justiciero, y rico hombre de Alcalá, de Moreto: "porque es lástima que el talento dramático de los actores, reconocido a todas luces, se emplee en la ejecución de piezas de esta clase, que, si eran tolerables en el tiempo en que se escribieron, no son conformes al presente estado de civilización del siglo ni al buen gusto ni a la moral misma." 20

Para ir saliendo a flote los dramáticos, lo mismo que en España, tenían que dar variedad al espectáculo alegrando los intermedios con bailes, cantos populares, tonadillas y trozos de óperas. La importancia del baile en los programas muestra que la gente del Nuevo Mundo había heredado la gran afición que siempre le tuvieron los españoles de todas las épocas. $E$ indudablemente hubiera sido me- 
nos el concurso a los teatros, sin el picante condimento de los bailes. Entre los bailes, en gran parte españoles aunque algunos son importaciones de otros países, se anunciaban la Jota aragonesa, solo de baile, bailes a dúo (Chalandé) y a trío (Las ninfas de Calipso), baile general (Paleoto), cuarteto de baile (Las habas verdes), Baile inglés y la Gabota (escrita a veces Gavota). Las boleras ${ }^{21}$ y tonadillas, producciones musicales típicamente españolas - de las tonadillas no se especifica por título más que la tarareable Trípili, trápa$l a^{22}$-, alternaban con oberturas, dúos y arias de varias óperas, entre las cuales casi ejercían las italianas un verdadero monopolio: el dúo de Tartufo y Clotilde (dos veces) - hay una ópera Clotilde, en dos actos, música de Coccia; un aria y un dúo del Tancredo (dos veces), letra de Rossi, música de Rossini; la obertura de Eduardo y Cristina, música de Rossini; la obertura de La muda de Portici, letra de Scribe y Delavigne, música de Daniel François Esprit Auber; un dúo del Barbero de Sevilla, letra de Sterbini, música de Rossini; la obertura del Barbero de Sevilla, probablemente la que fué compuesta por el preclaro compositor catalán Ramón Carnicer ; ${ }^{23}$ la obertura del Sitio de Corinto (dos veces), música de Rossini; un aria coreada de Semiramis, letra de Rossi, música de Rossini; la obertura de la Gazza ladra (dos veces), letra de Gherardini, música de Rossini; un dúo de Armida y Reinaldo, letra de Schmidt, música de Rossini; la obertura de la Limeña; un dúo de la Elisabetta, letra de Schmidt, música de Rossini; un dúo de la Ceneréntola, letra de Ferretti, música de Rossini; la opereta Quien porfía, mucho alcanza, música de Manuel Garcia. ${ }^{24}$ Esta lista descubre que el repertorio de la compañía de Martínez y Torres estaba bien provisto de partes de óperas rossinianas que gozaban a la sazón de igual predominio y prestigio en Madrid. ${ }^{25}$ Este catálogo de obras dramáticas y teatrales manifiesta que Bogotá, aunque en 1838-1840 era ya capital de una nación independiente, todavía dependía de Europa, especialmente de España, para sus diversiones.

E1 $1^{\circ}$ de diciembre de 1839 , con gran asombro del crítico literario del semanario El Observador, quien no creía que fuese posible que una compañía puramente cómica consiguiese representar una ópera, fué ejecutada a beneficio de la señora Requejo de Torres Clara de Rosenberg (letra de Rossi y música de L. Ricci). Escribió dicho crítico con agradable sorpresa: "La aria del ramillete fué cantada por la señora Marieta con muy buen gusto. Sentimos que no hubie- 
se sido tan aplaudida como lo merecía, tanto más cuanto que, no acompañada por el señor Torres como en el dúo siguiente, su exquisito oído la dirigió felizmente. Aunque no creemos que el carácter de Miguelón conviene al señor Gallardo, él lo desempeñó mucho mejor de lo que podía esperarse... El papel del conde de Valmor no está calculado para el señor Martínez. Es de sentirse que se suprimiese entre otras cosas la escena undécima del primer acto, en que la señorita Enriqueta habría desempeñado bien el solo que la correspondía." ${ }^{26}$ Para ver la ópera Clara de Rosenberg la entrada para adultos costó ocho reales (el doble cobrado por la función teatral en que fué dado el drama Torcuato Tasso), para niños cuatro. ${ }^{27}$

El francés A. Lemoyne, quien residió en la capital de Colombia de 1828 a 1839, describe con bastante exactitud el Coliseo, notando su capacidad e imperfecciones: "La ciudad de Bogotá... no tenía sino un pobrísimo teatro, cuya sala, limitada por dos galerías u órdenes de palcos, tenía poco más o menos la capacidad del Teatro de Variedades de París; pero la armadura era tosca y sin ningún adorno. El alumbrado se hacía simplemente por medio de velas de sebo $y$ de quinqués o velones, lo que indica que era detestable. Los palcos, lo mismo que el patio, no tenían asientos; era preciso enviarlos con anticipación, si uno quería sentarse." $28 \mathrm{El}$ anuncio inserto en El Observador referente a los programas para el domingo $1^{\circ}$ de marzo de 1840 , el lunes 2 y el martes 3 , descubre que la función principió en los tres días a las 4 de la tarde. ${ }^{29} \mathrm{El}$ reglamento del Coliseo prohibió definitivamente el fumar, ${ }^{30}$ pero algunos señores se empeñaron en desobedecer hasta que al fin se hizo un ejemplar castigo en el joven Fernando Bonilla, metiéndole en la cárcel. ${ }^{3 .}$ No tuvo resultado duradero esa severa medida, porque diez años más tarde se expresaban quejas sobre la grosería de los fumadores que llenaban los corredores y el patio de una nube de espeso humo que oscurecía el teatro. ${ }^{32}$

NOTAS

1 Aprovecho esta oportunidad para hacer constar mi gratitud al American Council of Learned Societies de Washington, D. C., por la beca que me permitió hacer investigaciones en Colombia durante el verano de 1942. También me es 
grato expresar aquí las gracias a mi buen amigo, el señor Enrique Ortega Ricaurte, Jefe del Archivo Histórico Nacional de Bogotá, por las acertadas indicaciones y ayuda que tuvo siempre la bondad de impartirme.

2 José Caicedo Rojas, Recuetdos y apuntamientos o cattas misceláneas, Bogotá, 1891 , p. 154.

3 Mesonero Romanos, escribiendo en 1832 acerca de la manera de formar las compañías para las provincias, da cabal idea del partido: ", . el empresario, que suele ser un actor antiguo o un individuo unido al teatro por lazos de consanguinidad, reúne las partes que le convienen, y sin más adelanto que el preciso para gastos del viaje y algunos días de asistencia a toda la compañía, cobra después durante las funciones de todo el año el 25 por 100 ó más del capital adelantado; y para hacer el reparto del producto de aquéllas con proporción, se figura a cada individuo lo que se llama partido; v.g.: $A$, primer galán, entra con partido de 40 reales; $B$, con 30 , y $C$, con 20; siendo la entrada 225 reales, tocará al primero 100 reales, al segundo 75 , y 50 al tercero, a razón de dos partes y media; pero como el producto en las provincias es corto, por muchas causas, apenas llegan a cobrar más de media parte o un cuarterón del partido". "Los cómicos en Cuaresma", en Panorama matritense, Obras de D. Ramón de Mesonero Romanos, Madrid, (s. a.), I, 62-63.

4 José María Cordovez Moure, Reminiscencias, Santa Fe y Bogotá, 6a edición, Bogotá, 1942, I, 64; Caicedo Rojas, op. cit., pp. 157-158; José Vicente Ortega Ricaurte, Historia critica del teatto en Bogotá, Bogotá, 1927. pp. 78-79.

5 Juan Francisco Ortiz, Teatro de Bogotá, teseña histótica, en La Guitnatda, publicada por José Joaquín Ortiz, 2a serie, Bogotá, 1856, pp. 302-303; Caicedo Rojas, op. cit., p. 170; Ortega Ricaurte, op. cit., p. 81.

6 Ibid.

7 El Atgos, trim. 5\%, Núm. 56, diciembre 16 de 1838, p. 233.

8 En Le Tasse, drama estrenado el 26 de diciembre de 1826 en el Théâtre Français y representado treinta veces, Alexandre Duval ha hecho algunas concesiones para conformarlo un poco con el nuevo espíritu romántico. "La première idée de la pièce est empruntée à Goethe; les personnages de condition vulgaire y coudoient les princes; le lieu de la scène n'y est point fixe et marqué, au sens où l'entendait Boileau; il change à chaque acte et s'étend même au delà de ces enceintes de palais que Voltaire avait assignées au poète tragique, comme une dernière et infranchissable limite." Véase Ch. Bellier-Dumaine, Alexandte Duval et son oeuve dramatique, Paris et Rennes, 1905, p. 175. La traducción de Ventura de la Vega se estrenó en el Teatro del Príncipe, el 6 de diciembre de 1828 y fué bastante popular, siendo representada en España hasta el año 1850. 
Véase J. Kenneth Leslie, Ventuta de la Vega and the Spanish Theatte (1820$1865)$, Princeton, 1940, p. 127.

9 El Atgos, trim. 50, Núm. 58, diciembre 30 de 1838, p. 242.

10 Quedo muy reconocido al distinguido profesor Guillermo Hernández de Alba, quien me dió generosamente el original de este programa.

11 Luis Carmena y Millán, Crónica de la ópeta italiana en Madrid desde el año 1738 hasta nuestros dias, Madrid, 1878, pp. 61-62, 64 y 69.

12 Ada May Coe, Catálogo bibliográfico y critico de las comedias anunciadas en los periódicos de Madrid desde 1661 hasta 1819, Baltimore, 1935, Extra vol, IX, 220.

13 El Argos, trim. 59, Núm. 58, diciembre 30 de 1838, p. 242; Núm. 60, enero 13 de 1839 , pp. 249-250; trim. 6\%. Núm. 78, mayo 19 de 1839. p. 320; El Observador, trim. $1^{\circ}$, Núm. 2, septiembre 29 de 1839, p. 8: Núm. 3, octubre 6, p. 16; Núm. 4, octubre 13, p. 20; Núm. 5, octubre 20. p. 20; Núm. 6 , octubre 27, p. 24; Núm. 7 , noviembre 3, p. 28 ; Núm. 8 , noviembre 10, p. 32; Núm. 9, noviembre 17, p. 38; Núm. 10, noviembre 24, p. 42; Núm. 12, diciembre 8, p. 50 ; Núm. 13, diciembre 15, p. 54; trim. $2^{\circ}$, Núm. 16 , enero 5 de 1840 , p. 66 ; Núm. 20 , febrero $2 ;$ Núm. 22. febrero 16, p. 90; Núm. 24, marzo 1\%, p. 98; El Censor del Observador y del Correo, Núm. 13, febreto 2 de 1840. Por lo regular en los avisos se omiten los nombres de los dramaturgos; para identificar los no citados he cotejado los títulos con los recogidos en las obras siguientes: A: Paz y Melia, Catálogo de las piezas de teatro que se conservan en el Departamento de Manuscritos de la Biblioteca Nacional, $2^{a}$ edición, revisada por Julián Paz, Madrid, 1934-1935. 2 tomos; E. Allison Peers, A History of the Romantic Movement in Spain, Cambridge, 1940, 2 tomos; Coe, op. cit.; Cayetano Alberto de la Barrera y Leirado, Catálogo bibliográfico y biográfico del teatro antiguo español, desde sus origenes hasta mediados del siglo XVIII, Madrid, 1860; Paul Patrick Rogers. The Spanish Drama Collection in the Oberlin College Libraty, Oberlin, 1940: Emilio Cotarelo y Mori, Isidoro Máiquez y el teatto de su tiempo, Madrid, 1902: Dionisio Hidalgo, Diccionario genetal de bibliografía española, Madrid, 1862-1881, 7 tomos; Ortega Ricaurte, op. cit., pp. 183-194; Gustavo Otero Muñoz. Resumen de historia de la literatura colombiana, $3^{\text {a }}$ edición. Bogotá. 1940 , p. 146. Me complace expresar aquí las gracias al profesor Nicholson B. Adams por los informes relativos a ciertas piezas con que me favoreció.

14 El Censor del Obsetvadot, loc. cit.

15 El original forma parte de la colección del doctor Guillermo Hernández de Alba.

16 Cordovez Moure nos ha dejado una excelente descripción del modo ingenioso empleado para obtener dinero en las funciones de beneficio. "En la 
puerta de entrada se armaba un solio, debajo del cual se sentaba el beneficiado, con una mesa al frente y una palangana de plata, para que al entrar los concurrentes arrojaran con estrépito el dinero que su generosidad les sugería: las dádivas eran recibidas con aplausos, la pasada en seco, con rechifla de los que permanecían en el sitio con el fin de hacer coacción sobre los majaderos." Véase op. cit.. p. 71 .

17 Para expresiones españolas contemporáneas que condenan desoladas la manía de traducir y adaptar tantos dramas extranjeros, véase Ramón de Mesonero Romanos. "Las traducciones", en Tipos y caracteres, Obras de Ramón de Mesoneto Romanos, Madrid, 1925, III, 155-156; Mariano José de Larra, "Carta a Andrés", I, 48, "Reflexiones acerca del modo de resucitar el teatro español", I, 112, "Teatros", I, 115-116, "Muerte del Pobrecito Hablador", I, 177, Obras completas de Fígaro, París, s. a. Para Mesonero Romanos, los mejores traductores de las piezas francesas e italianas durante los primeros años del siglo XVIII eran Félix Enciso Castrillón, Dionisio Solís y José María de Carnerero. Véase Trabajos no coleccionados, Madrid, 1905, II, 417-418. Larra alaba a Moratín como buen traductor, considera a Marchena inferior y acusa a Gorostiza de llamar originales "sus piraterías". Cf. "De las traducciones en el teatro", en Ideatio español, Madrid, s. a., p. 270.

18 Véase La vida de Madrid, en Obras completas, II, 251. Fígaro, en su análisis de las varias divisiones teatrales, con fina ironía califica una sección de "piececita de costumbres, sin costumbres, traducción de Scribe". Cf. "La vida teatral", en Ideario español, p. 264.

19 Peers, op. cit., I, 237, 294.

20 El Argos, trim. 59, Núm. 60, enero 13 de 1839, loc. cit.

21 "La bolera tiene un corte musical diferente de la seguidilla, pues ésta se hallaba vaciada en compás de 3 por 5 , y aquélla en compás de 3 por 8 , difiriendo, asimismo, en la rapidez del movimiento. Sin embargo, vemos poco a poco establecerse una confusión por lo que a las respectivas denominaciones atañe ..." Véase José Subirá, La tonadilla escénica, Madrid, 1929, II, 420. "Desde el último decenio del siglo XVII se entronizó la costumbre de rematar cada juego de coplas con unas boleras o sea unas seguidillas con estribillo, que musicalmente adoptaban un molde especial. Y estas boleras, a su vez, solian empalmar con un brevísimo número que anunciaba la conclusión del asunto y la presencia de la seguidilla, tirana o final con que iba a terminar la obra." Ibid., II, 206.

22 La Tonadilla del Tripili debe su título a la célebre tirana con el estribi1lo "Tripili, trápala" que finaliza la obra. La citada tirana gozaba de gran boga años después que cesaron de ser populares las tonadillas y se incluía en varias obras musicales de épocas posteriores. Acaso la compuso Laserna. Ibid., I, 227, 457-458; II, 390; III, 317-323. 
23 Ibid., I, 251-252.

24 Puesto que casi nunca se da el nombre del compositor me serví, para identificarlos, de Carmena y Millán, op. cit.; Cotarelo y Mori, op. cit.

25 En 1814 se dió a conocer en Madrid por primera vez la música de Rossini, pero no triunfó sin reservas hasta el día 30 de mayo de 1821 , cuando se estrenó La Gazza ladra, teniendo por intérprete a Laureana Correa: fué representada esta obra veinte veces aquel mismo año. Véase Cotarelo y Mori, op. cit., p. 377; Subirá, op. cit., I, 244. Mesonero Romanos, en un artículo redactado en el año de 1833, titulado "La filarmonía", califica de furor la afición y entusiasmo de los madrileños por la música vocal italiana: "Siguió asî la ópera, más o menos boyante, hasta que en 1825 se ajustó la compañía Montresor, desde cuya época no fué una afición la del público, sino un furor filarmónico. El mérito de los cantantes, la nueva pompa con que se exornó eI espectáculo, lo escogido de las funciones que se presentaron, fueron cosas de trastornar todas las cabezas, y llegó a tal punto el entusiasmo, que no solamente se les imitaba en el canto, sino en gesto y modales; se vestía a la Montresor, se peinaba a la Cortessi, y las mujeres varoniles a la Fábrica causaron furor todo aquel año." Véase Panotama matritense, en Obras completas, Madrid, s. a., I, 295. Bretón de los Herreros, a quien fatigaba la monomania por la música y la ópera italiana, llevó al teatro en 22 de marzo de 1839 una comedia-zarzuela satírica, El novio y el concierto, en la que compiten frente a frente la música popular española y la italiana, triunfando definitivamente aquélla. Véase El novio y el concierto, en Obtas, Madrid, 1883, Ir, 219-232.

26 El Observador, trim. 19. Núm. 12, diciembre 8 de 1839, pp. 49-50.

27 Ibid., Núm. 11, diciembre $1^{9}$ de 1839, p. 46.

28 "Bogotá en 1839", Boletin de historia y antigüedades, 1927, XVI, 458. (Este trozo está tomado de La Nouvelle-Grenade, Santiago de Cuba, La Jamaique et l'istme de Panama, Paris, 1880.) Otro francés, M. Alcides D'Orbigny, da una descripción casi idéntica. Véase "Bogotá en 1841", Boletín de historia y antigüedades, 1925, XV, 691. (E1 pasaje está tomado de Viajes a las dos Américas, traducción becha por J. M. González Benito.)

29 El Observador, trim. 2\%, Núm. 24, loc. cit.

30 Ortega Ricaurte, op. cit., p. 34.

31 El Censor del Observador y del Correo, Núm. 3, noviembre 3 de 1839.

32 El Sur-Americano, trim. 1\%, Núm. 6, septiembre 27 de 1849. 


\section{LA CONTRATA}

Los individuos abajo firmados se obligan por su espontánea y libre voluntad, a cumplir y observar religiosamente los artículos estipulados en la presente contrata, teniendo ésta toda la fuerza y valor de una escritura pública, y como si estuviese hecha ante cualquiera autoridad competente, pudiendo ser recombenido en juzgado todo el que se negase al cumplimiento de lo estipulado. que es del tenor siguiente:

Artículo $1^{9}$ - Todos están obligados a desempeñar, no sólo las tareas escénicas sino quanto pueda ser útil a la Sociedad y al aborro de gastos, que resultan en perjuicio de toda ella. Se comprende en este artículo la escritura de papeles y extractos: costuras de vestuarios para comparsas, pinturas de teatro, copias de música, dramas y saynetes o pitipiezas; y corren por turno con el armamento de escena, en obras de espectáculo, con arreglo a la etiqueta entregada por el Director al Tramoyista.

Artículo 2 - - Se nombrará una Junta de tres individuos de la Corporación, en la cual no podrá ser elegido el Director. Esta tendrá a su cargo revisar las cuentas, contratar los teatros, deliverar el presupuesto para cualquiera gasto estraordinario que exija el Director, y que sea de nesesidad para el mejor desempeño de los Dramas. Intervenir en los contratos de qualquiera compañía o actor que solicite trabajar en unión de esta Sociedad. Autorizar con sus firmas las cuentas generales y prestar su unánime consentimiento para cualquiera cantidad que fuese nesesario tomar, en clase de préstamo, pata viajes, fábricas de Teatros provisionales o útiles de escena.

Artículo $3^{\circ}$-Ningún individuo podrá separarse de la compañía sin el consentimiento unánime de la Junta y el Director; y el que lo hiciese por si, sin este requisito, será responsable a los perjuicios que la Sociedad reclame, causados por su separación.

Árticulo $4^{\circ}-$ No habrá clase fija en esta compañia y los repartos de papeles se harán con arreglo al mejor desempeño y éxito del Drama, por combenio amistoso entre las partes principales, quedándoles a todos el derecho de insinuar al Director qualquiera pieza que gusten exhivir en el turno mensal.

Articulo $5^{\circ}-$ El tamo de canto se hará por turno entre las dos damas, sin perjuicio de las funciones en que ambas tengan que trabajar en intermedio u ópera. Si cualquiera otra señora, del mismo ramo, fuese incorporada en la compañía, será bajo este mismo orden.

Artículo 6-.El Director tendrá a su cargo la dirección de escena; el reparto de obras con el tiempo nesesario para el estudio; las cuentas particulares y generales de compañía, con el requisito anterior; entregar las voletas cada 
noche de función, tomando un recivo del número de ellas; nombrar por turno un individuo de compañía que, concluída la función, reciva un tanto de las voletas y palcos vendidos en la noche al comisionado para ello; y preparar con anticipación y el consentimiento de la Junta, los enseres que fuesen de nesesidad pata la ejecución del drama anunciado.

Artículo $7^{\circ}$ - La Junta y el Director, tendrán a su cargo mantener el buen orden interior, amonestando amistosamente a cualquiera socio que introdusca el desorden, faltando a la moderación y comportamiento que exije el decoro y crédito de la compañía, para lo cual se hará un reglamento, autorizado por juez competente y firmado por los espresados, que se fijará en el vestuario.

Artículo $8^{\circ-}$-Ningún individuo de compañía podrá disponer de palco o voleta sin que sea de su cuenta y cargo. Sólo tendrán entrada franca los criados o criadas que conducen equipajes y ayudan a vestir.

Artículo 90-Toda la compañía es responsable a los créditos que se contraigan con anuencia de la Junta y cuyas partidas hayan sido empleadas en servicio de la misma; por lo cual no se hará gasto alguno ni éste será abonable por la Sociedad sin que comparescan los recivos de los artesanos o trabajadores que hubiesen percivido cantidades.

Artículo 10.-Sólo por enfermedad legítima y reconosida por facultativo podrá eximirse qualquiera socio de cumplir con sus deveres, y el que se le justificase hacerlo por malicia o por infringir perjuicio a la Sociedad, será responsable a los perjuicios y cargos que ésta misma le exijiese.

Ártículo 11.-Los gastos de viaje se pagarán de los fondos generales de compañía, si huviese existente el contingente para ello, y de no, tomando el Director con anuencia de la Junta, la cantidad nesesaria al crédito, y deviendo ser lo primero que se cubta tan luego que se dé principio al trabajo, con preferencia a cualquiera otro pago; pero sólo la manutención, si se combiniesen hacerla unidos, será de gasto general, pero cabalgaduras y demás gasto se cubrirá con arreglo al sueldo que cada uno disfruta.

Artículo 12.-Tan luego que la compañia cubra sus créditos pendientes de viajes, etc., se comenzará a formar un fondo dejando para ello el líquido producto de una función mensal, que deverá ser estraordinaria. Este fondo existirá en poder del individuo que designe la compañia y sólo se sacará de él para los gastos estraordinarios de teatro o para viajes, deviendo reintegrarse la cantidad que se gaste lo más pronto posible, a fin de que no sufra menoscabo, sino por el contrario que vaya en aumento. Cualquiera cantidad que de él se saque será con recivo del Director. Si algún individuo se separase de la Corporación, por unanimidad de votos de la Junta y el Director, tendrá su derecho a salvo para reclamar el tanto que le correspondiese en el fondo existente. 
Artículo 13. - La Junta y el Director podrán recombenir por tres veces a qualquiera individuo de la Sociedad, que por su mal manejo perjudique en su crédito a la Corporación. Y si absolutamente no cediese a la insinuación y continuase con escándalos, podrán reunirse para tomar otras providencias $y$ deliverar su separación, sin que le quede al causante ningún derecho a reclamos de ninguna especie.

Artículo 14.-Se asignará por la Junta y el Director una multa para el individuo que falte a los ensayos (que se consideren nesesarios) sin justa y legítima causa; estas multas pasarán al fondo general y en la cantidad que se reuna no tendrán parte los que huviesen hecho las faltas.

Artículo 15.-Si para la exhivición de un drama fuese nesesario ocupar algunos individuos que no pertenescan a la compañia, la Junta designará el tanto que deven percivir con arreglo a su trabajo, o por noche, o por un tanto fijo mensal, y así se jusgase más combeniente a la seguridad de su desempeño.

Artículo 16.-El señor Agustín Ramos, como profesor de música, tendrá el cargo de la enseñanza, ensayos, instrumentar las piezas nesesarias, apuntar las de canto, contratar orquesta con la equidad posible y vijilar en los cobros de puerta, los ratos que le sea posible asistir a ellos; por este trabajo disfrutará al sueldo que tiene señalado a partido, sin perjuicio de los cuatro pesos fijos que goza por función, por la dirección de orquesta y tocar el primer violín, no entendiéndose esta cláusula en los beneficios, que no podrá exijir nada.

Artículo 17.- - Los productos de las funciones se repartirán con arreglo al partido que cada uno disfruta, según delivere la Junta, o por noche, $\circ$ por mes, o número determinado de funciones; y si fuese de los modos últimos, los fondos existirán en un individuo de la misma Junta, que elija la compañia.

Artículo 18.- - Los sueldos por partido que disfruta la compañia, serán los siguientes:

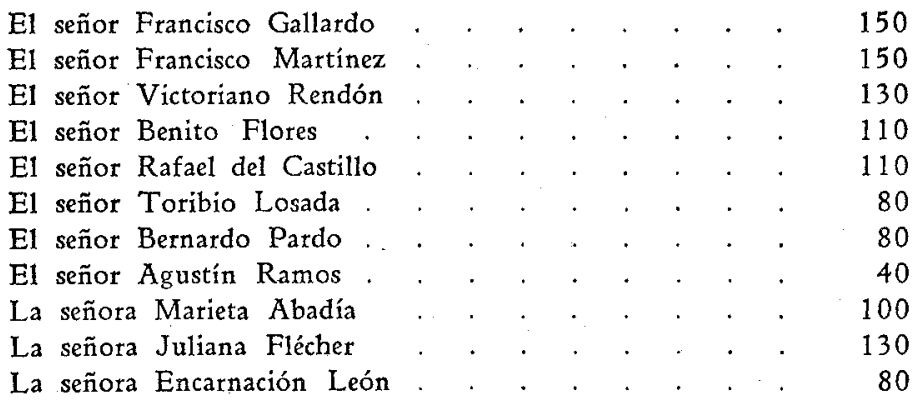

Artículo 19.-Ningún individuo o individuos que sean agregados a esta compañía, por superiores que sean sus actitudes, podrá gozar sueldo mayor que 
el que disfruta el Director y el galán, y lo mismo se entendetá en la clase de damas.

Artículo 20.-Todo actor que se agregue a esta Corporación y sólo sea útil para un accesorio o intermedio, se pagará con arreglo a su abilidad, según estipulación que haga la Junta, para un tanto por función en la noche que trabaje.

Artículo 21.- Todos los individuos de esta compañía están obligados a franquear, sin interés ninguno, su archivo de obras dramáticas y música de piezas cantantes $y$ concertantes; $e$ igualmente prestarse amistosamente qualquiera vestuario de que alguno caresca y él tubiese. Esta condición se entiende entretanto que cada uno se abilita de lo nesesario, a cuyo efecto se prefija el perentorio plazo de seis meses.

Artículo 22.-Habrá beneficios particulares en el año cómico, en regla de propotción, bajo el método siguiente:

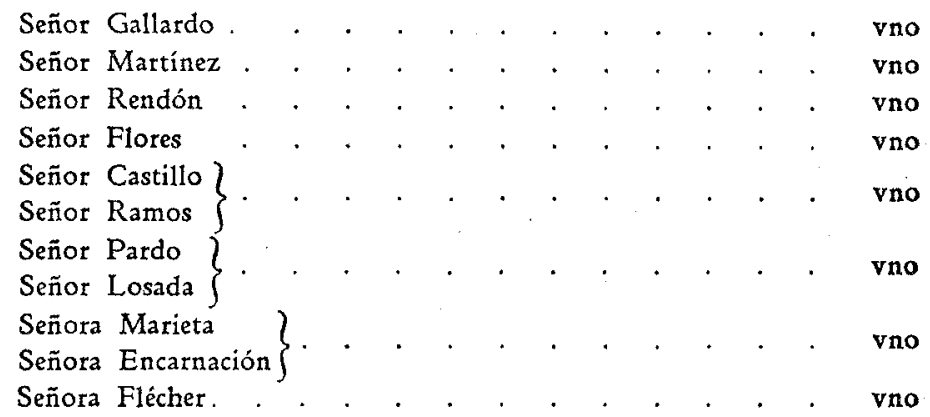

Estos se harán en el año cómico, uno en cada mẹs, por sorteo general, quedando al advitrio (sic) del agraciado la elección de obra.

Artículo 23.-Esta contrata no tendrá término prefijado por no ser de necesidad el señalarle, pues no pudiendo separarse ninguno en particular ni deshacerse la compañía sin combenio general de toda ella, no es nesesario este requisito.

Artículo adicional:

Para satisfacer los créditos pendientes, tanto de los individuos que pertenecían a la compañía del señor Martínez, como de los que fueron socios de la del señor Torres, se dejará en fondo la tercia parte del tanto que a cada uno corresponda por mes o por función, y estas datas se depositarán en persona de confianza, para que ésta vaya satisfaciendo, conforme vaya recaudando y entregando los recivos o documentos. 
Segundo adicional:

El señor Rendón, como inteligente en el ramo de pinturas, se hará cargo de dirigir los útiles de esta clase que fuesen nesesarios para las obras, abonando la Sociedad el gasto de materiales y el de uno o dos oficiales, según se nesesite para el trabajo.

$Y$ haviendo sido leída, revisada y aceptada por todos los subscritos, se firmó en Bogotá a 29 de nobiembre de 1838.

\author{
Francisco Martínez. \\ Juliana Flécher. \\ Benito Flores. \\ Bernardo Pardo. \\ Toribio Lozada. \\ Victoriano Rendón. \\ Agustín Ramos. \\ Rafael del Castillo. \\ Por mí y mi esposa Marieta Abadia, \\ Francisco Gallardo. Encarnación León.
}

En seis de diciembre del mismo año se eligieron los individuos que devian componer la Junta económica de la Sociedad, y fueron nombrados los señores Gallardo, Rendón y Flores.

Como Director,

Francisco Martínez.

Habiéndose reunido los principales individuos que formaban la compañía del señor Martínez con el señor Eduardo Tortes, por sí y por su familia, con el objeto de formar una sola, se tomó en consideración la contrata celebrada por los primeros y se sometió a ella el señor Torres con las siguientes variaciones:

$1^{a}$-No queda el señor Torres obligado a la última parte del artículo $1^{\circ}$, en cuanto a correr por turno con el armamento de escena en las obras de espectáculo, conforme a la etiqueta entregada por el Director al Tramoyista.

$2^{\text {a }}-\mathrm{E} 1$ comprometimiento del artículo $3^{2}$ se entenderá con el señor Torres y su familia mientras la compañía dure en esta ciudad, de manera que al marchar ésta el señor Torres queda en libertad de separarse o continuar.

$3^{a}$-Si la última parte del artículo $6^{9}$ en donde dice "preparat con anticipación y el consentimiento de la Junta los enseres que fuesen de necesidad para la ejecución del drama anunciado," se entiende que deve ser esta obligación del que nombre el Director en turno, como expresa más arriba el artículo, queda también eximido el señor Torres.

$4^{\text {a }}$ - Los créditos de que habla el artículo $9^{\circ}$ se entienden que son los que contraygan la compañía desde la incorporación del señor Torres. 


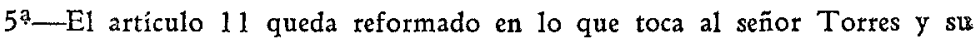
familia, conforme a la variación $2^{\text {a }}$

$6^{2}$-E1 artículo 12 y 17 quedan reformados en cuanto al señor Torres, pues él recivirá lo que le corresponda por cada función, tanto a él como a su familia.

$7^{\text {a }}$-En cuanto al artículo 18 , se hizo el convenio siguiente con respecto a los sueldos.

E1 señor Tortes tendrá. . . . .\$150.- Su señora, \$120.- La señorita Henriqueta, $\$ 150$. - La señorita Eloisa, $\$ 90 .-\mathrm{Y}$ el señor Requejo, $\$ 100$, la señora Marieta Abadía de Gallardo, $\$ 120$.

$8^{a}$-Del artículo 21 queda eximido el señor Torres en cuanto a los bestidos, pero no en cuanto a las piezas dramáticas y de música, tanto cantantes como concertantes, siendo de advertir que las óperas se darán para que se copien, tomándose este trabajo los demás individuos de la compañía, siendo de cargo de ella el papel fenecente y quedando a favor del mismo señor Torres las copias que se saquen.

$9^{\text {a }}$-Los beneficios del señor Torres y familia se arreglaron así: el señor Torres uno, su señora otro, la fide (sic) mayor otro, señor Requejo y señorita Eloisa otro, y se variaron del artículo 22, poniendo uno a la señora Aba-. día y otro al señor Castillo.

10a - El primer artículo adicional se teformó en la parte que dispone que los que sepan para pagar créditos se deposite en persona de confianza, y los: individuos que pertenezcan a la compañia del señor Torres se entenderán directamente con él para el pago de réditos que hayan contraído en común.

$11^{\text {a }}$-Se darán cuatro funciones supernumerarias con el objeto de pagat las deudas, y el total de lo que a cada uno toque en ellas se entregará al señor Torres por los individuos que pertenezcan a su compañía, y al señor Granados por los que pertenezcan al señor Martínez, sin perjuicio de que si con estas: cantidades no quedase cubierto, todos se convendrán en dar las demás que fuesen necesarias.

$Y$ por consentir todos los que formaban la reunión en estas variaciones, $y$ que por ser su voluntad, quedan obligados a ellas como por escritura pública, para que faltando se les compela a su cumplimiento por las vías legales, firmant el presente combenio con los individuos que han propendido a la reunión, en Bogotá a 20 de diciembre de 1838 .

Francisco Martínez.

Como testigo,

Felipe Sandino.
Por toda mi familia, Eduardo de Torres.

\section{Januario Triana}


En la ciudad de Bogotá a los veintiún días del mes de diciembre de mil ochocientos treinta y ocho, teunidos los infrascritos, como miembros de la Junta establecida por la contrata que precede, con el único objeto de determinar sobre lo que el Director de la compañía hacía presente, con relación a que el señor Eduardo de Torres había manifestado no querer la permanencia de la Junta, y leídos los artículos de la adición, hemos resuelto: "queda disuelta la Junta que nos componiamos y las facultades que se nos habían conferido las delegamos íntegras y con toda amplitud en dicho Director señor Francisco Martínez, a quien antes de esta nuestra dimición le cedemos el derecho por toda la compañia y por nosotros." Para la mayor seguridad y para que pueda todo individuo ser obligado a su observancia en juicio, fuera de él o como el Director lo estime legal, firmamos esta acta enmendada: Diciembre.

\section{Victoriano Rendón.}

Benito Flores.

\section{Ftancisco Gallardo.}

De requerimiento del interesado señor Francisco Martínez se protocoliza el instrumento que antecede, en mi registro de instrumentos públicos del presente año. Bogotá, quince de febrero de mil ochocientos treinta y nueve. En este estado se pagó el derecho de registro como lo acredita la voleta que aquí agregada a la letra dice: (Aquí la de fojas 78.) Ut supra.-

\section{José Lucio de Elorga, escribano interino.}

\section{REPUBLICA DE LA NUEVA GRANADA}

Administración de Recaudación del Cantón de Bogotá, febrero 16 de 1839

En esta fecha pagó el escribano José Lucio de Elorga cuatro reales de registro de un instrumento que se protocoliza en su registro de instrumentos públicos, y por el cual están comprometidos a trabajar en compañía en el teatro. dé esta capital, los señores Francisco Martínez, Francisco Gallardo, por sí y por su esposa la señora Marieta Abadia, Eduardo de Torres por sí y su familia compuesta del señor Requejo, la señora Requejo y las señoritas Enrriqueta y Eloisa de Torres, Victoriano Rendón, Benito Flores y su esposa Encarnación León, Rafael del Castillo, Toribio Losada, Bernardo Pardo, Agustín Ramos y Juliana Flécher.

José Martínez Recamán.

Harvey Leroy JoHnson, Northwestern University. 
